\title{
Practical Aspects of the Design and Construction of a Small Cable Roof Structure
}

\author{
Vinicius Fernando Arcaro, Luiz Carlos de Almeida \\ University of Campinas, Campinas, Brazil \\ Email: vinicius.arcaro@gmail.com
}

How to cite this paper: Arcaro, V.F. and de Almeida, L.C. (2017) Practical Aspects of the Design and Construction of a Small Cable Roof Structure. Open Journal of Civil Engineering, 7, 453-467. https://doi.org/10.4236/ojce.2017.73031

Received: August 8, 2017

Accepted: August 29, 2017

Published: September 1, 2017

Copyright ( $) 2017$ by authors and Scientific Research Publishing Inc. This work is licensed under the Creative Commons Attribution International License (CC BY 4.0).

http://creativecommons.org/licenses/by/4.0/

(c) (i) Open Access

\begin{abstract}
Cable roof structures have only become widespread in large span structures in the latter part of the twentieth century. However, they still represent a relatively new form of roof construction, especially as in the present case of a small span innovative structural solution. The contribution of this text to the structural engineering community lies in the increased interest in building simple cable roof structures. Since its completion in September 1996, this small cable roof structure has been recognized as an interesting architectural and structural example. The text describes aspects of the design and construction of a small cable roof that was designed as a roof for an open-air theater stage for the city of Sao Jose do Rio Pardo, Sao Paulo, Brazil. A cable network, in the shape of a hyperbolic paraboloid surface, is anchored in a reinforced concrete edge ring. The projection of the ring's axis onto the ground plane is an ellipse. Workers with specialized training were employed in the various stages of the construction, which was completed in September 1996.
\end{abstract}

\section{Keywords}

Cable Roofs, Hypar Roofs, Tension Structures

\section{Introduction}

The cable roof network, initially in the form of a hyperbolic paraboloid surface, is anchored in a ring of reinforced concrete whose axis projects an ellipse in the horizontal plan. The larger and smaller axes of the ellipse measure $20.00 \mathrm{~m}$ and $13.00 \mathrm{~m}$, respectively. The network is formed by an orthogonal mesh 10 by 6 , which is parallel to the ellipse axes. Both end points of the larger axis are $1.75 \mathrm{~m}$ below the surface center, while both end points of the smaller axis are $1.00 \mathrm{~m}$ above the surface center. The center of the surface is $4.50 \mathrm{~m}$ above the ground. A wire rope with diameter of 1 inch $(25.4 \mathrm{~mm})$ and composed of galvanized steel 
wires of high resistance was specified for the cables. Cable clamps were used at the intersection of two cables and purlins were fixed over the cable clamps in the direction parallel to the ellipse's smaller axis. A pre-painted steel sinusoidal sheet was used for roof cladding. The cross section of the edge ring is rectangular measuring $1.00 \mathrm{~m}$ wide by $0.45 \mathrm{~m}$ high. The edge ring axis follows the form of the hyperbolic paraboloid surface. The ring is sustained by four identical reinforced concrete columns with $3.71 \mathrm{~m}$ high and rectangular cross section measuring $0.25 \mathrm{~m}$ by $0.50 \mathrm{~m}$. The axis of the smaller moment of inertia of the rectangle is tangent to the ellipse equation. The structure is shown in Figure 1. Notice the rotation of the cross section of the edge ring.

\section{The Hyperbolic Paraboloid Surface Equation}

The hyperbolic paraboloid surface, which is necessary for the description of the undeformed configuration of the cable network, can be written as:

$$
Z=A\left(\frac{x}{a}\right)^{2}+B\left(\frac{y}{b}\right)^{2}
$$

The value of $A$ is equal to $-1.75 \mathrm{~m}$, the value of $B$ is equal to $1.00 \mathrm{~m}$, the value of $a$ is equal to $10.00 \mathrm{~m}$ and the value of $b$ is equal to $6.50 \mathrm{~m}$.

\section{Finite Element Discretization of the Structure}

The finite element discretization of the structure is shown in Figure 2. The cable network was discretized with 96 cable elements. Reference [1] describes this element and explains a procedure to tension the cable network. The edge ring was discretized with 72 beam elements, of the type often used in the linear analysis of structures. This element is suitable because small displacements are expected for the edge ring. The discretized edge ring is defined by a closed poly-

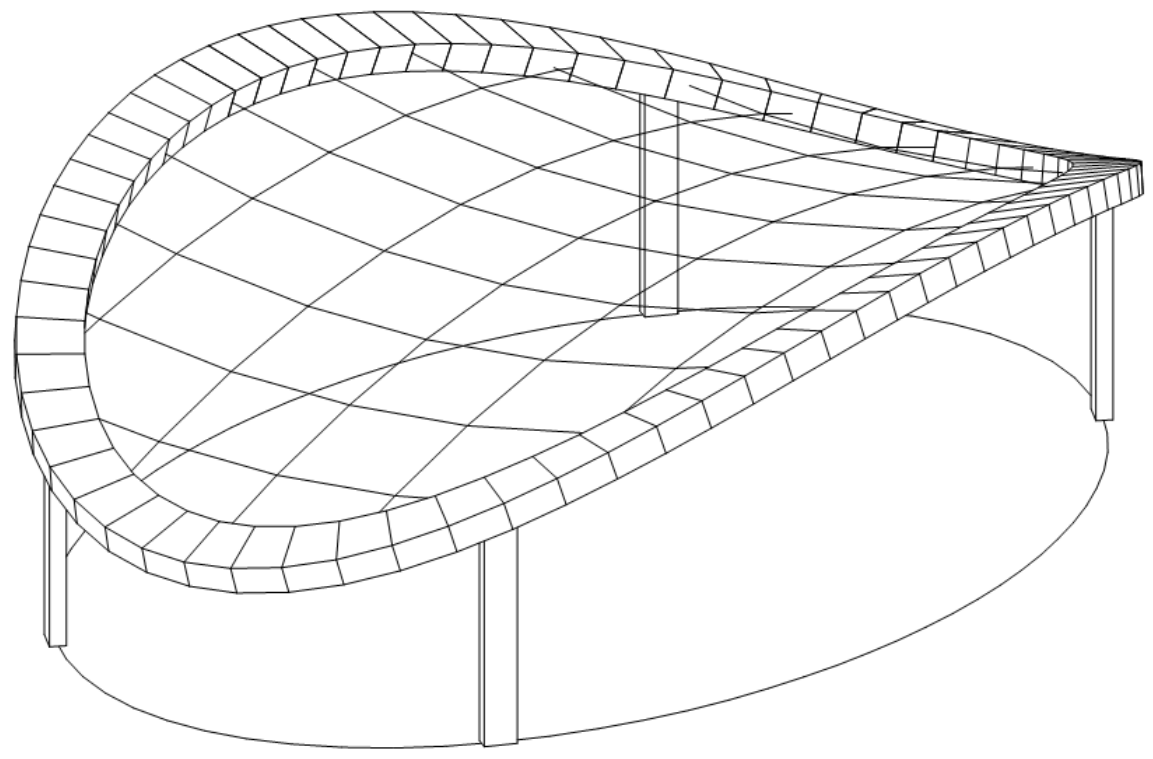

Figure 1. Structure. 


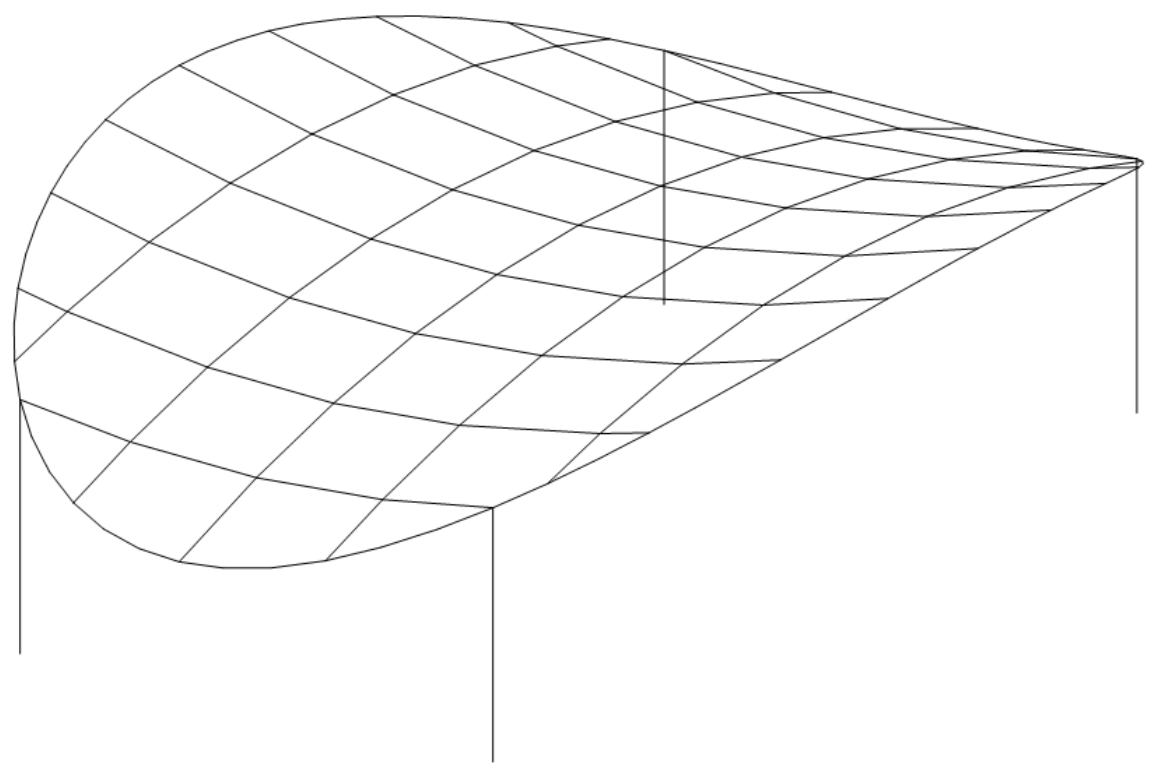

Figure 2. Structural model.

gonal line, whose vertexes belong to the hyperbolic paraboloid surface. Only one beam element was used for the discretization of each column. Reference [2] is a public domain 3D finite element program for the design and analysis of light structures. The program element library includes cable elements, membrane element, frame element and spring element. The computer source code written in Ada95, the executable code for Windows and examples is available for download. The input files used to analyze this structure are included as example number 2.

Figure 3 shows the node numbering of the structural model. Column 1 is linked to nodes 6 and 73, column 2 is linked to nodes 30 and 74, column 3 is linked to nodes 42 and 75 and column 4 is linked to nodes 66 and 76 . The connection between the edge ring and the column can obstruct the ring's rotation about its axis, favoring the appearance of torsional moment in the ring. To minimize this torsional moment, the columns were hinged at the ring connection and clamped at its the base. Moreover, the axis of the smaller moment of inertia of the column's cross-section was placed tangentially to the ellipse equation, because the pinned hypothesis for the connection will not be verified perfectly in the real structure.

\section{Material Specifications}

A wire rope with a diameter of 1 inch $(25.4 \mathrm{~mm})$ and composed by 37 galvanized steel wires of high resistance was specified for the cables. The metallic area is equal to $3.829170 \mathrm{~cm}^{2}$, the elastic modulus is equal to $14710 \mathrm{kN} / \mathrm{cm}^{2}$, the break force is equal to $456 \mathrm{kN}$, and the thermal coefficient is equal to $0.0000115 / \mathrm{C}$. Reference [3] discusses the benefits of structural cables previously submitted to tensioning to eliminate the initial lengthening caused by the helical configure- 


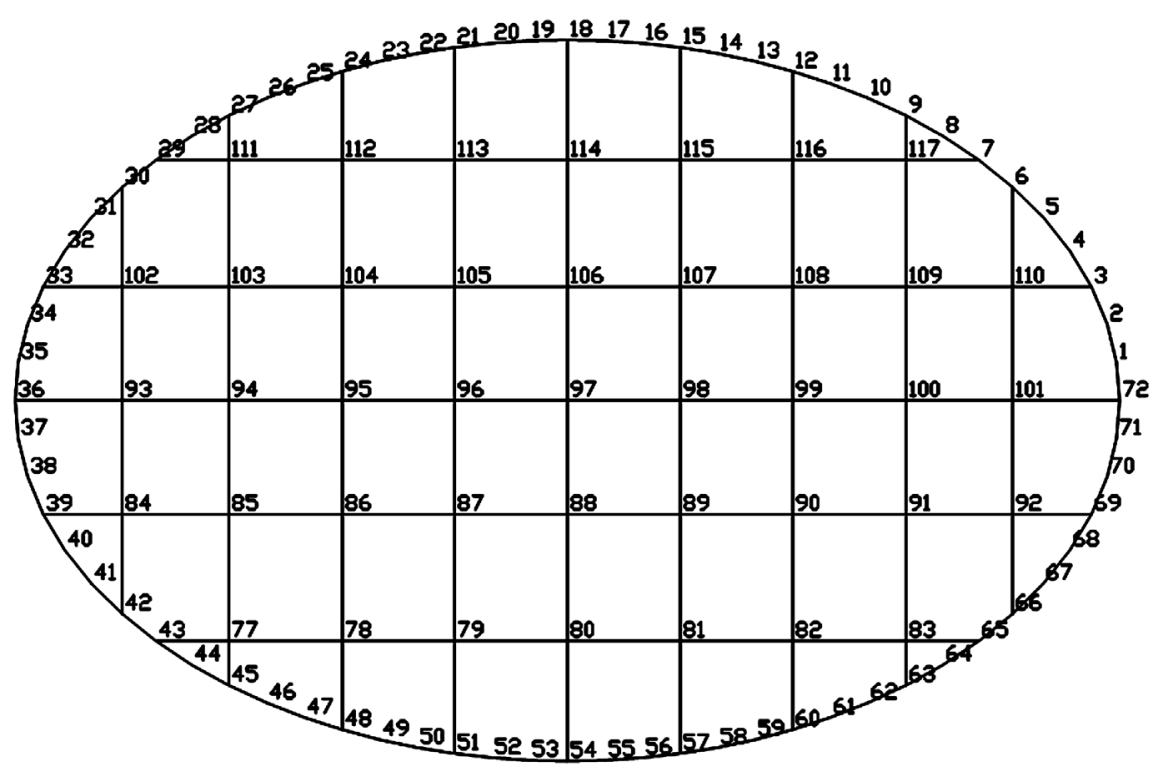

Figure 3. Binding cable connected to the edge ring.

tion of the wires. The specification for the concrete is given by an elastic modulus equal to $2746 \mathrm{kN} / \mathrm{cm}^{2}$, transverse elastic modulus equal to $1144 \mathrm{kN} / \mathrm{cm}^{2}$, and a specific weight equal to $24.5 \mathrm{kN} / \mathrm{m}^{3}$.

\section{Loading Cases}

At the time of the construction, no wind loads guidelines were available for this roof shape. In the absence of guidelines and considering the characteristics of the region where the structure was built, an ad hoc estimate for the design wind loads was a downward pressure of $470 \mathrm{~Pa}$ and an upward pressure of $706 \mathrm{~Pa}$. For the cable network, the wind load was considered acting orthogonal to the hyperbolic paraboloid surface, which is the undeformed configuration of the cable network. Reference [4] provides guidelines for loading cases and corresponding safety factors for structural applications of steel cables for buildings. Notice that a deformed configuration of the cable network does not define a hyperbolic paraboloid surface. For the edge ring, the load of the lateral wind was considered acting orthogonal to its faces. The eight loading cases considered for the design of the structure are shown in Table 1 , where $\mathrm{L}$ is the loading case number, $\mathrm{SF}$ is the safety factor for the cable force, $\Delta \mathrm{T}$ is the temperature change, (1) is the vertical pressure applied to the cable network due to the permanent or live load, (2) is the orthogonal pressure applied to the cable network due to the wind load and (3) is the orthogonal pressure applied to the edge ring due to the lateral wind load. The direction of the lateral wind is horizontal and is further determined by an angle specified in degrees in relation to the $\mathrm{X}$-axis.

\section{Cable Network}

Reference [1] describes the cable element. The cable element has three states: 
Table 1. Loading cases.

\begin{tabular}{cccccc}
\hline & & & \multicolumn{3}{c}{ Pressure $(\mathrm{Pa})$} \\
\cline { 4 - 6 } & $\mathrm{SF}$ & $\Delta \mathrm{T}(\mathrm{C})$ & $(1)$ & $(2)$ & $(3)$ \\
\hline 1 & 2.0 & 0 & 0 & 0 & $0,0^{\circ}$ \\
2 & 2.0 & 0 & 0 & 0 & $0,0^{\circ}$ \\
3 & 2.2 & 0 & -93.2 & 0 & $0,0^{\circ}$ \\
4 & 2.7 & 0 & -289.3 & 0 & $0,0^{\circ}$ \\
5 & 2.0 & 0 & -93.2 & -470.7 & $588.4,0^{\circ}$ \\
6 & 2.0 & 0 & -93.2 & 706.1 & $588.4,90^{\circ}$ \\
7 & 2.0 & -15 & -289.3 & 0 & $0,0^{\circ}$ \\
8 & 2.0 & 15 & -289.3 & 0 & $0,0^{\circ}$ \\
\hline
\end{tabular}

1) Normal state-a simple truss element, 2) Cut state-a truss element with a cut in its length in order to apply tension to the element and 3) Tension state-a truss element with constant tension. By default, all cable elements start in the normal state. The state of each cable element can be changed at the start of a loading case. In the cut state, a constant cut value is applied in the element's undeformed length. In the tension state, the element shows a constant tension value regardless of its nodal displacements. A constant cut value is equivalent to a constant tension value in the sense that they both produce the same internal forces. A cable network is tensioned by applying constant cut or constant tension to selected elements of the cable network. A binding cable element is an element of the cable network that is connected to the edge ring. Figure 3 shows that there are 10 binding cable elements in the $\mathrm{X}$ direction and 18 binding cable elements in the $\mathrm{Y}$ direction. Applying tension to the cable network in a loading case will be specified by applying tension to the binding cable elements. Notice that applying tension to elements of a cable network is accomplished in practice by applying tension through a hydraulic jack. Table 2 shows the state for the binding cable elements in the $\mathrm{X}$ direction at the start of each loading case, where $\mathrm{L}$ is the loading case number. The cross-sectional dimensions were determined by repeating the following steps: start with the initial dimensions, calculate the critical bending moments, and then determine the dimensions needed to resist these moments.

\section{Structural Nonlinear Analysis}

The stable equilibrium configurations correspond to local minimum points of the total potential energy function. The total potential energy is minimized using the BFGS quasi-Newton method and employs a line-search procedure through cubic interpolation as described in [5]. The source and executable computer codes are available for download from the corresponding author's website. The computer code generates a script file for AutoCAD using only basic commands in an attempt to be independent of AutoCAD version. 
Table 2. Binding elements X.

\begin{tabular}{ll}
\hline L & State \\
\hline 1 & Self weight only \\
2 & Tension 196.1 MPa \\
3 & Equivalent cut \\
4 & Equivalent cut \\
5 & Equivalent cut \\
6 & Equivalent cut \\
7 & Equivalent cut \\
8 & Equivalent cut \\
\hline
\end{tabular}

\section{Results for the Cable Network}

Table 3 shows, for each loading case L, the minimum and maximum displacement for the cable network nodes. For loading cases 1 and 2, the displacements are relative to the undeformed configuration of the cable network. For the remaining loading cases, the displacements are relative to the configuration obtained after applying tension to the binding cable elements in the $\mathrm{X}$ direction. Notice that when considering all loading cases, the minimum and maximum displacements in the $\mathrm{Z}$ direction occur for the wind pressure and wind suction loading cases respectively. The maximum absolute value of the displacement in the $\mathrm{Z}$ direction divided by the average diameter of the ellipse is approximately $1 / 300$. Table 4 shows, for each loading case $L$, the maximum axial force in the cable network elements. Note that when considering all loading cases, the maximum axial force occurs for the wind suction loading case. The value of this force divided by the value of the break force is approximately $1 / 5$. An attempt to use a cable with smaller a cross-sectional area did not yield better results because it became necessary to increase the tensioning force to keep the vertical displacements acceptable, which, in turn, resulted in unacceptable internal forces in the edge ring.

\section{Results for the Edge Ring}

Table 5 shows the critical internal forces for the edge ring, where $\mathrm{N}$ is the node number and $\mathrm{L}$ is the loading case number. The internal forces are shown in the element reference system, whose $\mathrm{Y}$-axis is parallel to the smaller dimension of its rectangular cross-section. Notice that the maximum axial compression occurs for the loading case of temperature decrease.

\section{Results for the Columns}

Table 6 shows the critical internal forces for the columns, where $\mathrm{N}$ is the node number and $\mathrm{L}$ is the loading case number. The internal forces are shown in the element reference system, whose $\mathrm{Y}$-axis is parallel to the smaller dimension of its rectangular cross-section. 
Table 3. Displacements (mm).

\begin{tabular}{ccccc}
\hline \multirow{2}{*}{$\mathrm{L}$} & \multicolumn{2}{c}{ Minimum } & \multicolumn{2}{c}{ Maximum } \\
\cline { 2 - 5 } & $\mathrm{Z}$ & Node & $\mathrm{Z}$ & Node \\
\hline 1 & -29 & 18 & 8 & 36 \\
2 & -69 & 97 & 0 & 66 \\
3 & -7 & 97 & 0 & 72 \\
4 & -15 & 97 & 1 & 36 \\
5 & -36 & 97 & 2 & 72 \\
6 & -3 & 72 & 54 & 97 \\
7 & -16 & 97 & 1 & 54 \\
8 & -15 & 97 & 2 & 36 \\
\hline
\end{tabular}

Table 4. Cable forces $(\mathrm{kN})$.

\begin{tabular}{ll}
\hline L & Force \\
\hline 1 & 20.40 \\
2 & 75.10 \\
3 & 72.90 \\
4 & 68.53 \\
5 & 65.04 \\
6 & 93.55 \\
7 & 76.81 \\
8 & 60.28 \\
\hline
\end{tabular}

Table 5. Critical internal forces $(\mathrm{kN}, \mathrm{kNm})$, edge ring.

\begin{tabular}{|c|c|c|c|}
\hline \multirow{2}{*}{$\mathrm{N}$} & FX & FY & $\mathrm{FZ}$ \\
\hline & MX & MY & MZ \\
\hline \multicolumn{4}{|c|}{ Axial Compression Force, $\mathrm{L}=7$} \\
\hline \multirow[t]{2}{*}{64} & 312.00 & -38.00 & -64.00 \\
\hline & -9.02 & -19.32 & -0.39 \\
\hline \multirow[t]{2}{*}{65} & -315.00 & 47.00 & 64.00 \\
\hline & 9.02 & 71.49 & -34.62 \\
\hline \multicolumn{4}{|c|}{ Shear Force $\mathrm{Y}, \mathrm{L}=5$} \\
\hline \multirow[t]{2}{*}{41} & 222.00 & -80.00 & 125.00 \\
\hline & 14.02 & -248.70 & 10.10 \\
\hline \multirow[t]{2}{*}{42} & -219.00 & 89.00 & -125.00 \\
\hline & -14.02 & 146.22 & -79.63 \\
\hline \multicolumn{4}{|c|}{ Shear Force Z, L = 5} \\
\hline \multirow[t]{2}{*}{30} & 219.00 & 89.00 & -125.00 \\
\hline & -14.02 & -146.12 & 79.63 \\
\hline \multirow[t]{2}{*}{31} & -222.00 & -80.00 & 125.00 \\
\hline & 14.02 & 248.70 & -10.10 \\
\hline \multicolumn{4}{|c|}{ Torsional Moment, $\mathrm{L}=1$} \\
\hline \multirow[t]{2}{*}{27} & 103.00 & -54.00 & -19.00 \\
\hline & 40.99 & 117.48 & -28.73 \\
\hline
\end{tabular}




\section{Continued}

\begin{tabular}{cccc}
\hline 28 & -105.00 & 62.00 & 20.00 \\
& -40.99 & -101.89 & -18.04 \\
& \multicolumn{1}{c}{ Bending Moment $\mathrm{Y}, \mathrm{L}=5$} & \\
& 253.00 & -6.00 & -7.00 \\
36 & 3.24 & -476.31 & -115.62 \\
& -253.00 & 13.00 & 5.00 \\
& -3.24 & 480.23 & 109.34 \\
& Bending Moment Z, L $=1$ & -6.00 \\
& 65.00 & 1.00 & -196.03 \\
& 2.84 & 210.94 & 8.00 \\
& -65.00 & 6.00 & 194.27 \\
\hline
\end{tabular}

Table 6. Critical internal forces $(\mathrm{kN}, \mathrm{kNm})$, columns.

\begin{tabular}{|c|c|c|c|}
\hline \multirow{2}{*}{$\mathrm{N}$} & FX & FY & $\mathrm{FZ}$ \\
\hline & MX & MY & $\mathrm{MZ}$ \\
\hline \multicolumn{4}{|c|}{ Axial Compression Force, $\mathrm{L}=5$} \\
\hline \multirow[t]{2}{*}{75} & 190.00 & -3.00 & 32.00 \\
\hline & 0.00 & -118.86 & -11.47 \\
\hline \multirow[t]{2}{*}{42} & -179.00 & 3.00 & -32.00 \\
\hline & 0.00 & 0.00 & 0.00 \\
\hline \multicolumn{4}{|c|}{ Shear Force Y, L = 1} \\
\hline \multirow[t]{2}{*}{75} & 161.00 & -5.00 & 19.00 \\
\hline & 0.00 & -71.59 & -17.85 \\
\hline \multirow[t]{2}{*}{42} & -150.00 & 5.00 & -19.00 \\
\hline & 0.00 & 0.00 & 0.00 \\
\hline \multicolumn{4}{|c|}{ Shear Force Z, L = 5} \\
\hline \multirow[t]{2}{*}{73} & 190.00 & -4.00 & 34.00 \\
\hline & 0.00 & -125.53 & -12.94 \\
\hline \multirow[t]{2}{*}{6} & -179.00 & 4.00 & -34.00 \\
\hline & 0.00 & 0.00 & 0.00 \\
\hline \multicolumn{4}{|c|}{ Bending Moment $\mathrm{Y}, \mathrm{L}=5$} \\
\hline \multirow[t]{2}{*}{73} & 190.00 & -4.00 & 34.00 \\
\hline & 0.00 & -125.53 & -12.94 \\
\hline \multirow[t]{2}{*}{6} & -179.00 & 4.00 & -34.00 \\
\hline & 0.00 & 0.00 & 0.00 \\
\hline \multicolumn{4}{|c|}{ Bending Moment $\mathrm{Z}, \mathrm{L}=1$} \\
\hline \multirow[t]{2}{*}{75} & 161.00 & -5.00 & 19.00 \\
\hline & 0.00 & -71.59 & -17.85 \\
\hline \multirow[t]{2}{*}{42} & -150.00 & 5.00 & -19.00 \\
\hline & 0.00 & 0.00 & 0.00 \\
\hline
\end{tabular}




\section{Support Reactions}

Table 7 shows the critical support reactions, where $L$ is the loading case number.

\section{The Steel Reinforcement}

The reinforced concrete structure was designed in the ultimate limit state according to the criteria established by the Brazilian standard of reinforced concrete structures in force at the time as recommended in [6]. The characteristic strength of the materials was $20 \mathrm{MPa}$ for the concrete and $500 \mathrm{MPa}$ for the steel. In the connection between a column and the edge ring, an approximate hinged connection was built with the reinforcement details as recommended in [7]. These details aid the rotation of the concrete ring section. Figure 4 shows the reinforcing steel bars for the edge ring and for the columns. The bar diameter is shown in millimeters.
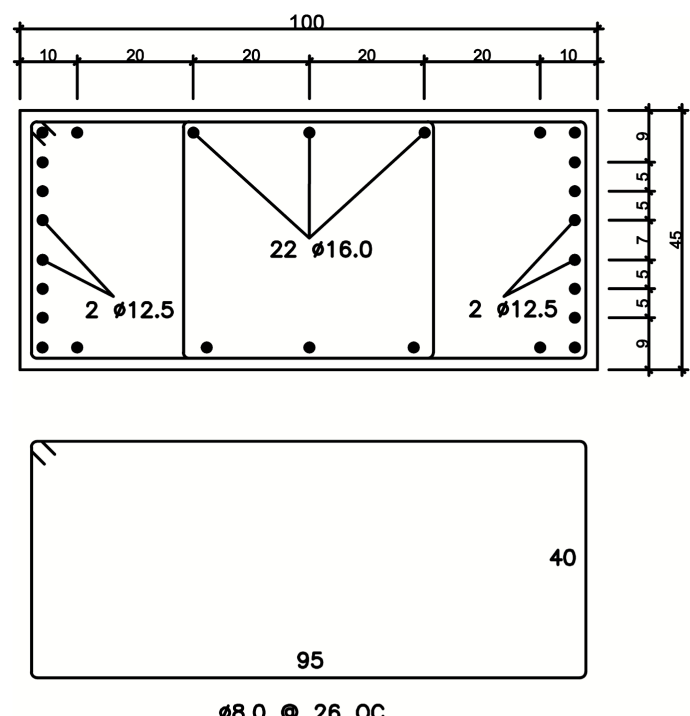

$\$ 8.0 \odot 26 \mathrm{OC}$

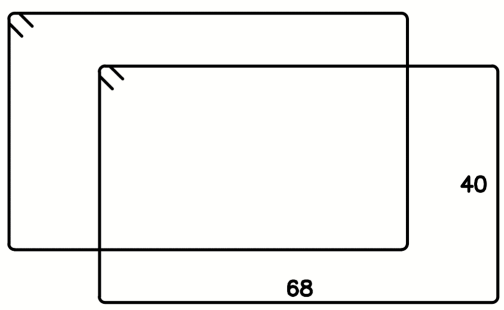

$2 \varnothing 8.0 \odot 13$ OC

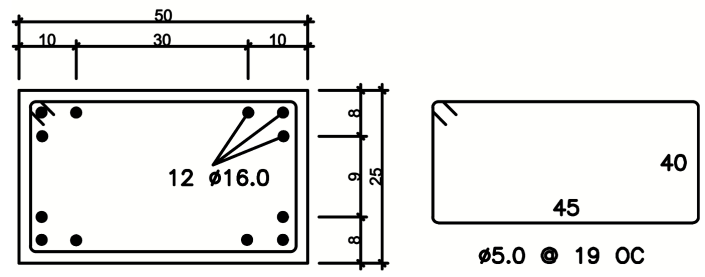

Figure 4. Edge ring and column reinforcing steel. 
Table 7. Support reactions for node $73(\mathrm{kN}, \mathrm{kNm})$.

\begin{tabular}{cccccc}
\hline L & FX & FY & FZ & MX & MY \\
\hline 1 & -18 & 9 & 161 & -34.03 & -65.41 \\
2 & -13 & 10 & 161 & -36.58 & -49.92 \\
3 & -16 & 11 & 166 & -42.46 & -58.35 \\
4 & -20 & 15 & 176 & -55.02 & -76.00 \\
5 & -28 & 20 & 190 & -73.55 & -102.58 \\
6 & 2 & -1 & 130 & 4.22 & 5.88 \\
7 & -20 & 15 & 176 & -55.21 & -73.55 \\
8 & -21 & 15 & 176 & -54.72 & -78.36 \\
\hline
\end{tabular}

\section{The Construction}

Due to the complex geometry of the edge ring, a surveyor was necessary during the wood form construction. The reinforcement bars were cut and folded at the construction site. The reinforcement steel for the edge ring was placed inside its wood form to guarantee the procedures specified in reference [6]. The concrete placement for the edge ring was applied with a pump and conducted continuously to ensure a monolithic element. Workers with specialized training were employed in the various stages of the construction, which was completed in September/1996. Figure 5 and Figure 6 show the reinforcement bars crossing at the connection between the column and the edge ring to approximate a hinged connection. The concrete hinge details are explained in reference [7]. Figure 7 shows the carpentry work of the concrete form for the edge ring. Figure 8 shows the steel reinforcement for the edge ring. Figure 9 shows the anchor plate for the cable connector. Figure 10 shows the placing of the concrete. Figure 11 shows the concrete edge ring. Figure 12 shows the cable network installation. Figure 13 shows the cable connector. Figure 14 and Figure 15 show the installation of the roof cladding. Figure 16 shows the audience seats. Figure 17 shows the complete structure as viewed from outside.

\section{Concluding Remarks}

The contribution of this text to the structural engineering community lies in the increased interest in building simple cable roof structures. Since its completion in September 1996, this small cable roof structure has been recognized as an interesting architectural and structural example. It has received international attention by being entered into the following websites: 1) Structurae [8], which is a database concerned with the structural aspects of the documented projects and the technical aspects of its construction and design, and 2) Tensinet [9], which consists of 22 participating organizations related to tension structures (manu- 


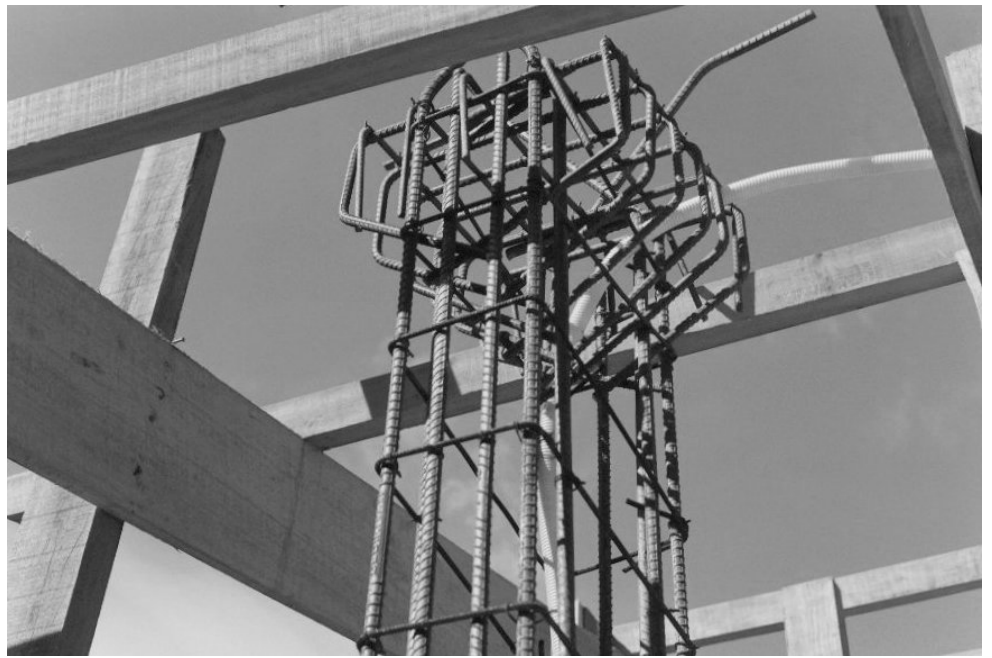

Figure 5. Approximate a hinged connection column and edge ring.

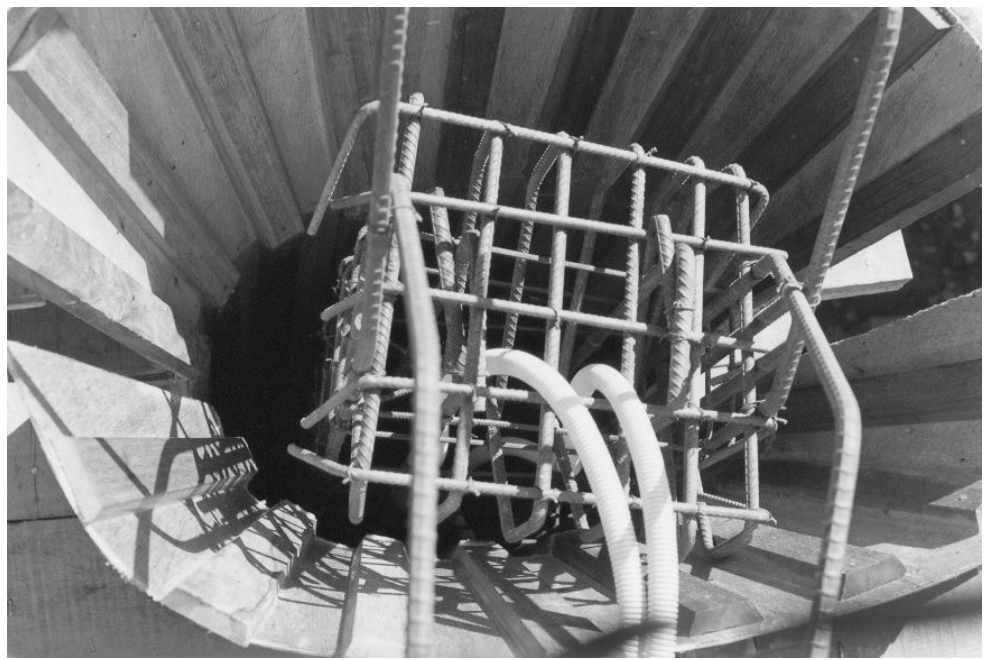

Figure 6. Column and edge ring to approximate a hinged connection.

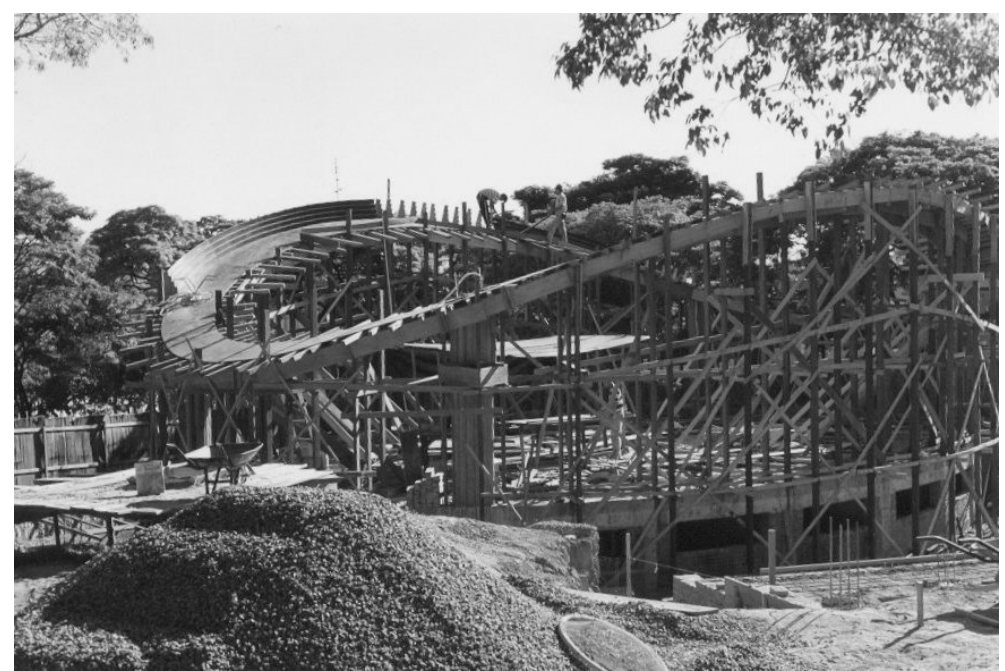

Figure 7. Carpentry work for the edge ring. 


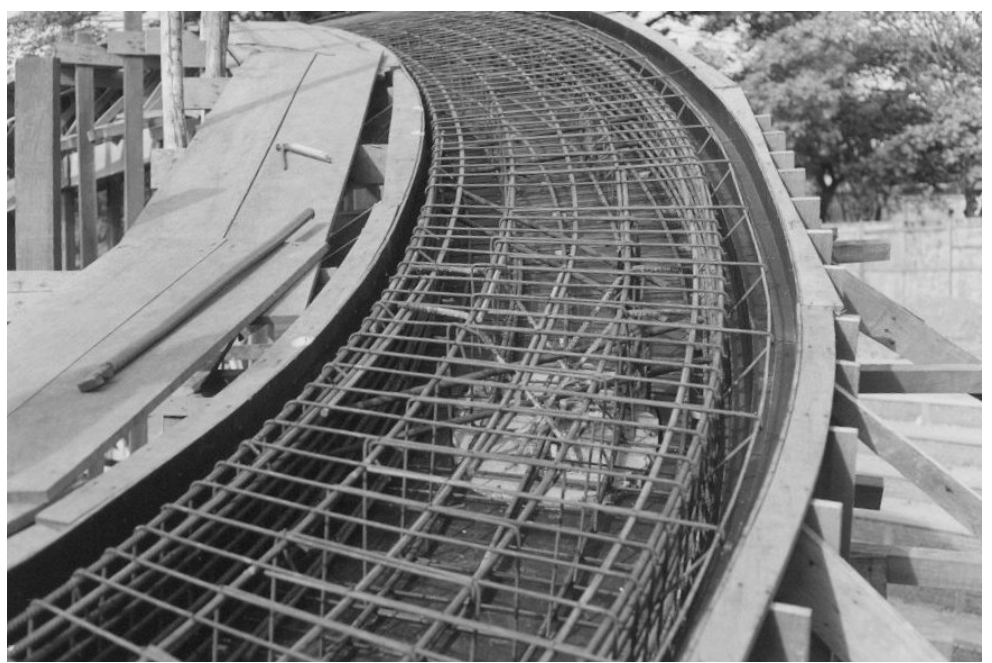

Figure 8. Edge ring reinforcing steel.

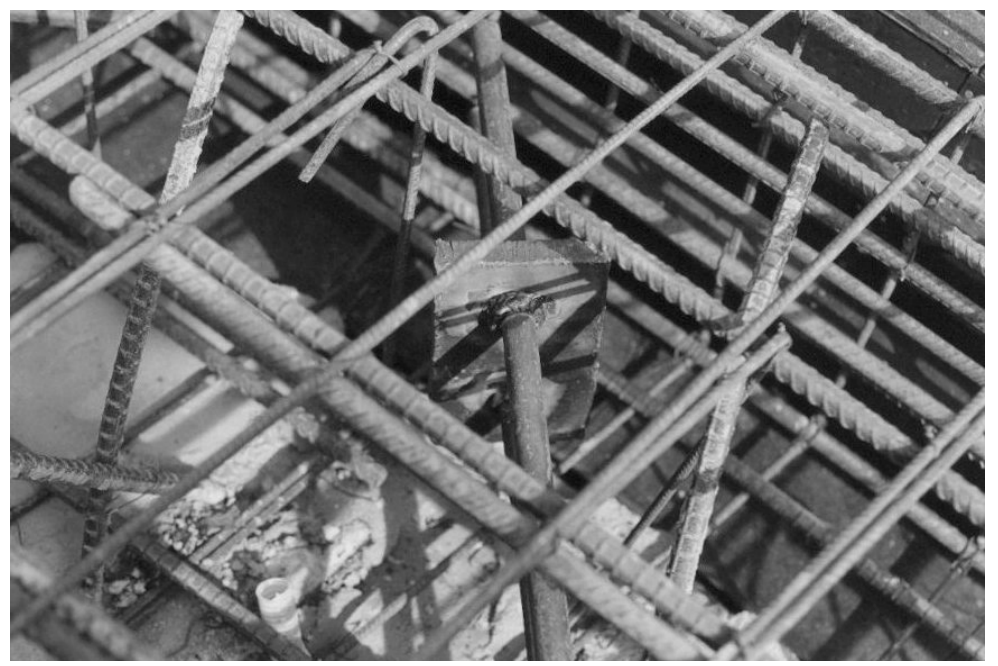

Figure 9. Anchor plate for the cable connector.

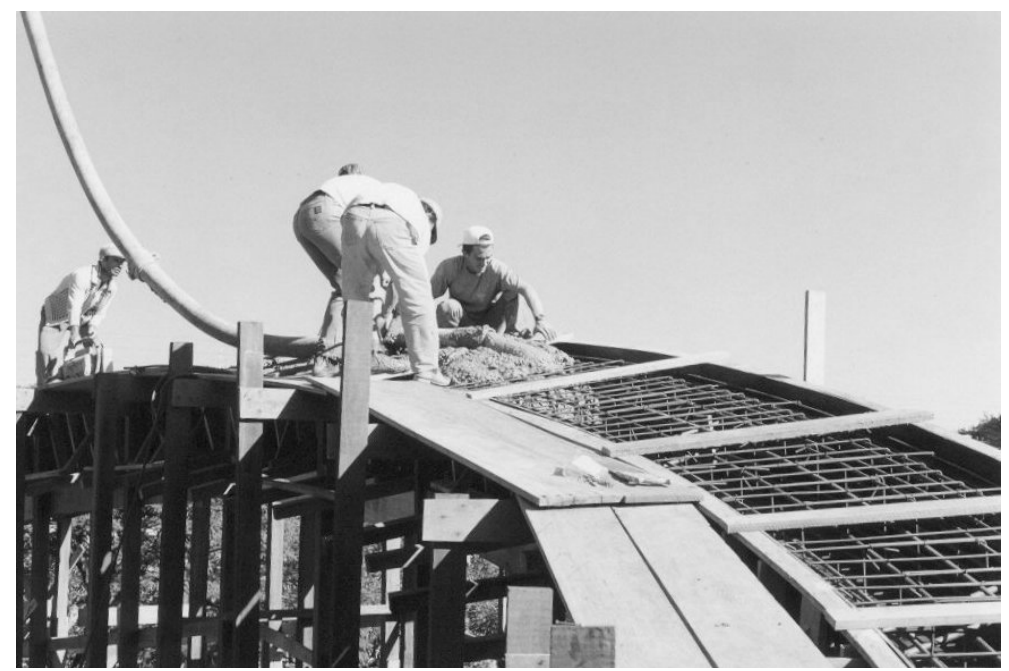

Figure 10. Placing concrete. 


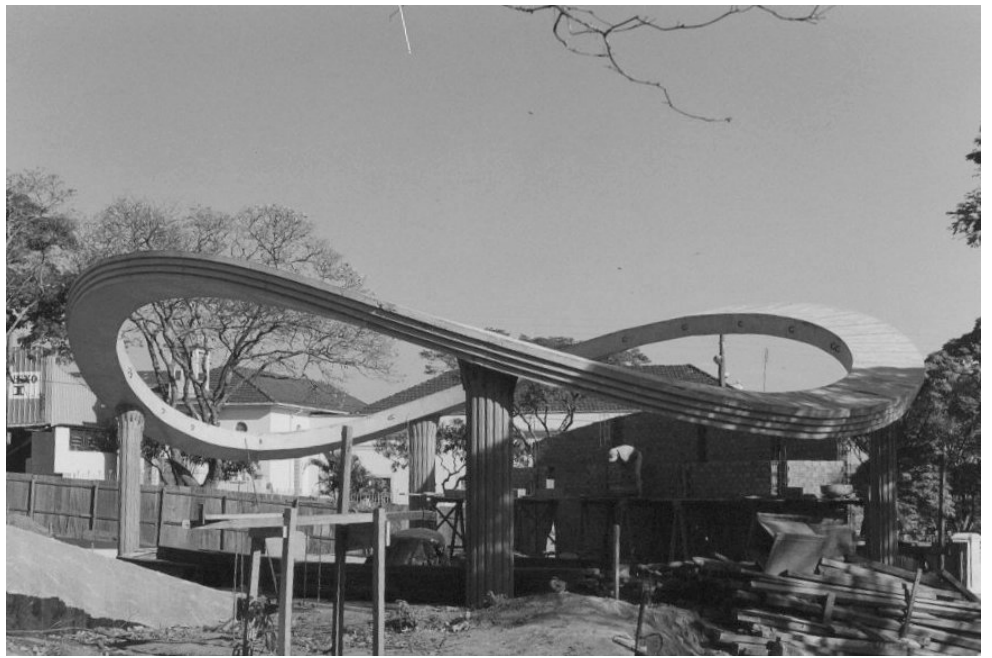

Figure 11. Concrete edge ring.

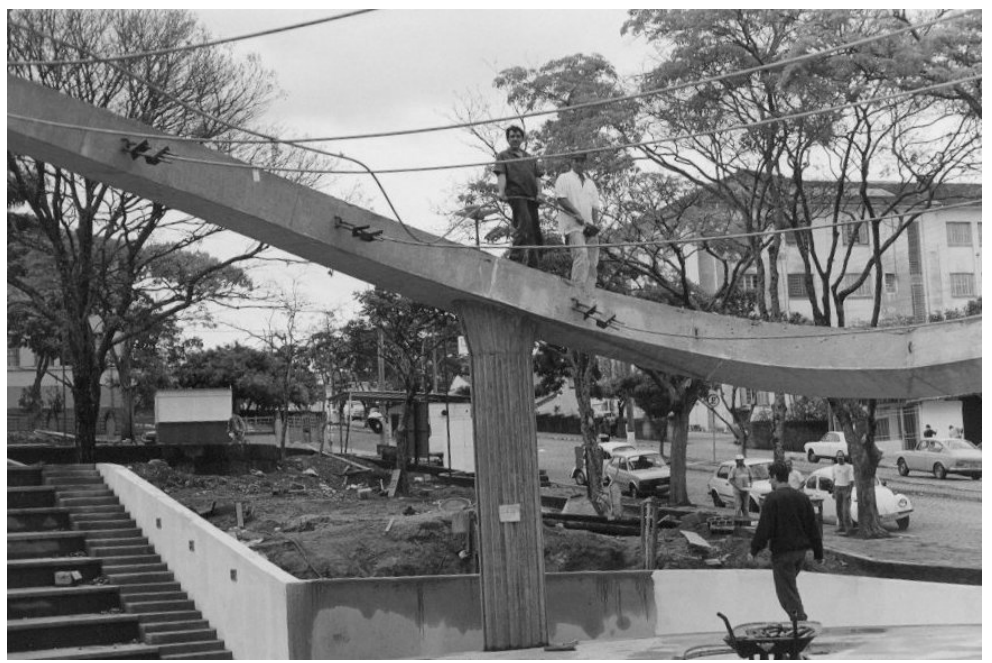

Figure 12. Cable network installation.

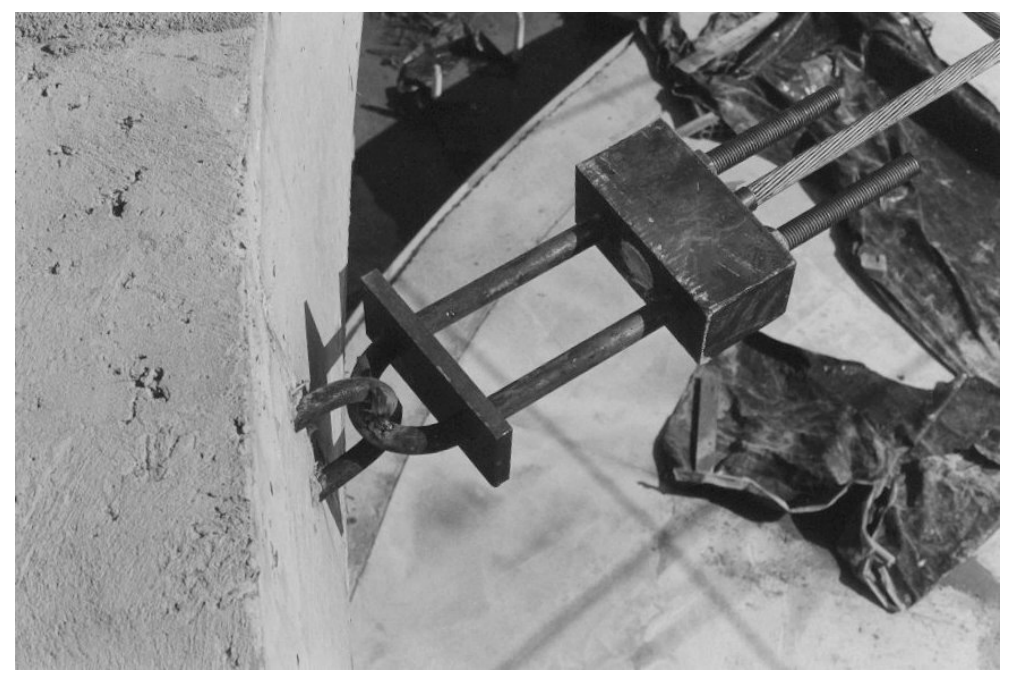

Figure 13. Cable connector. 


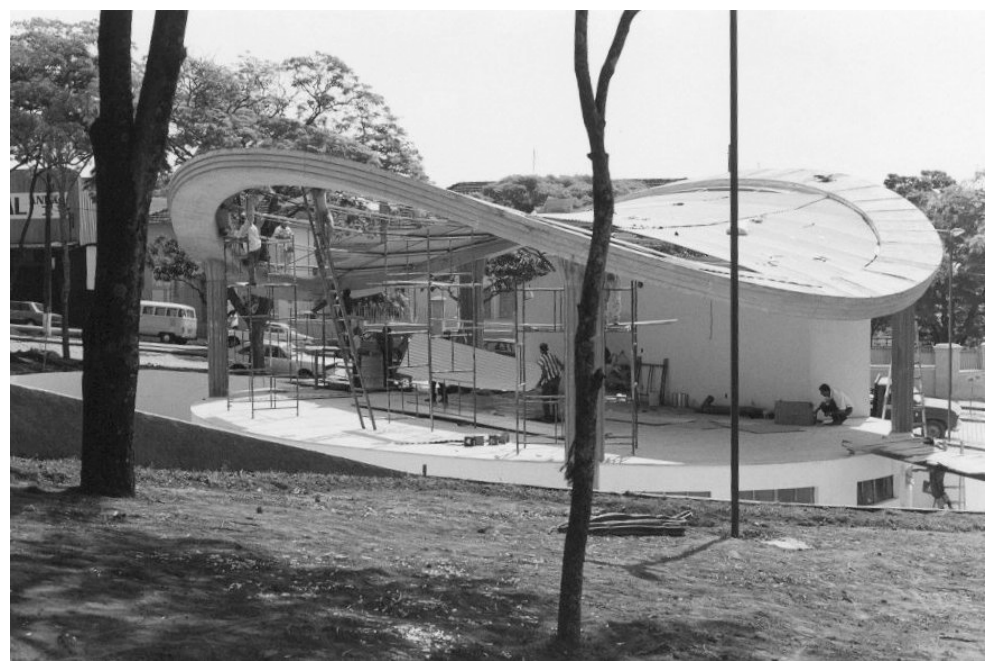

Figure 14. Roof cladding installation.

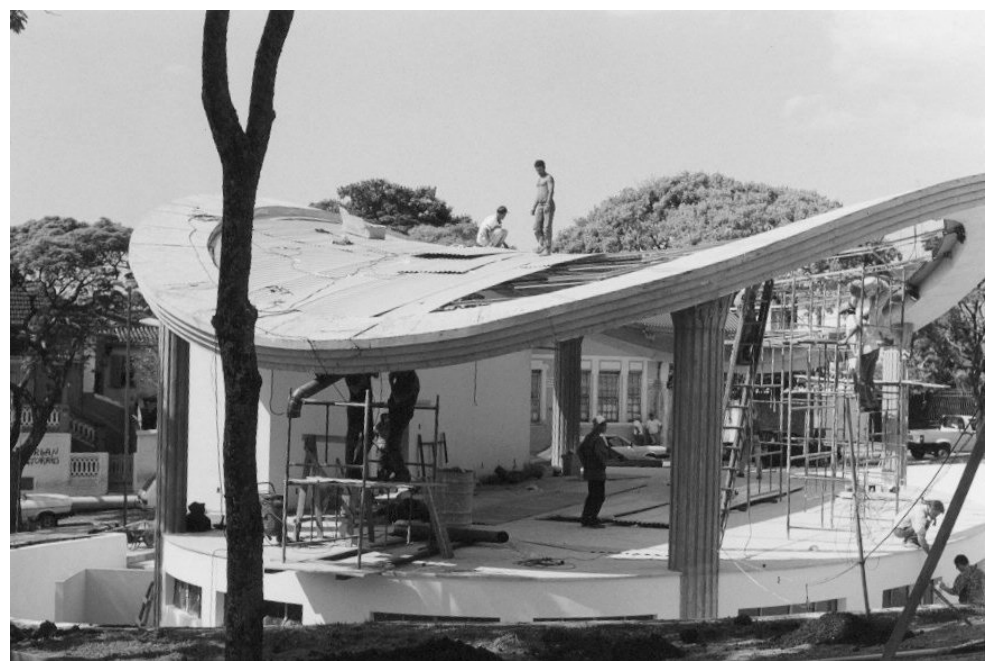

Figure 15. Roof cladding installation.

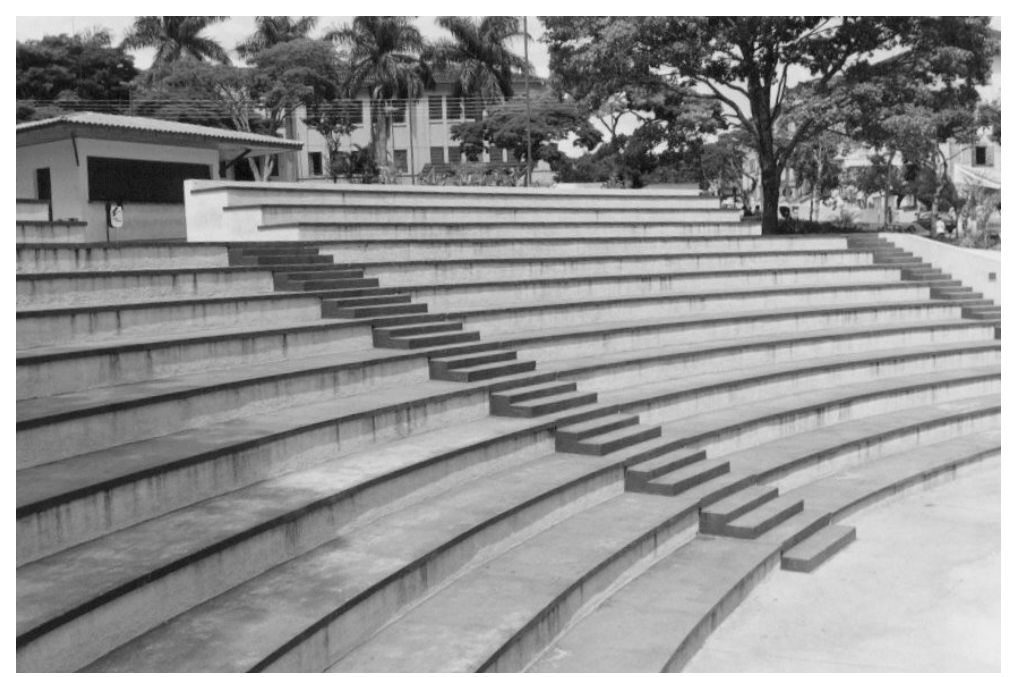

Figure 16. Audience seats. 


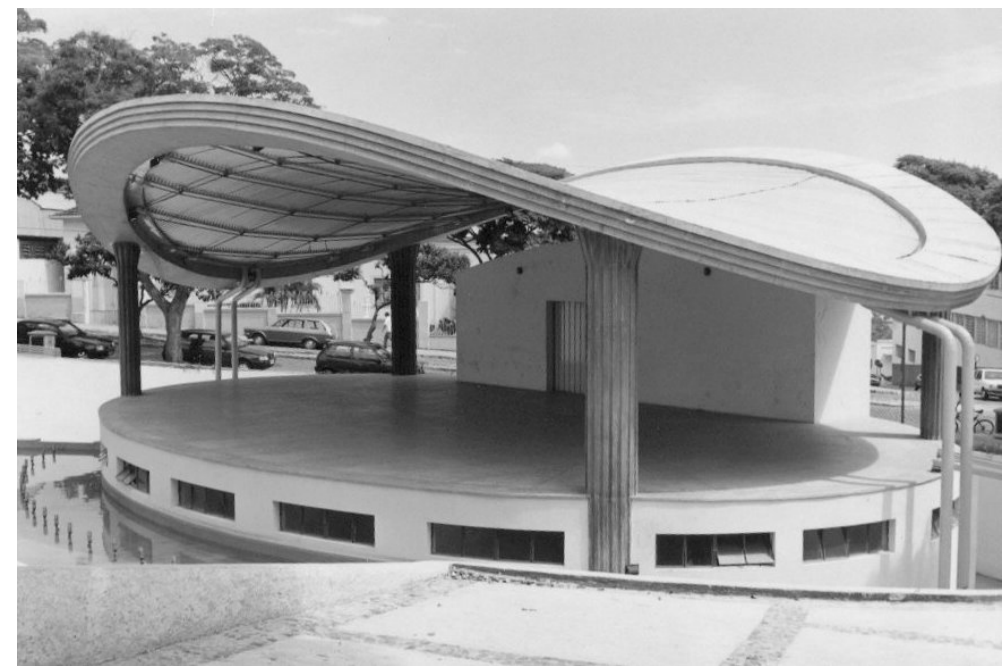

Figure 17. Complete structure.

facturers, producers, engineering offices, architecture offices, and universities) with representatives from nine European Union member states.

\section{References}

[1] Arcaro, V. (2002) A Simple Procedure for Analysis of Cable Network Structures, Proceedings of the Fifth International Conference on Space Structures, Surrey, 19-21 August, Thomas, Telford, 585-592. https://doi.org/10.1680/ss5v1.31739.0063

[2] LIGHTS Computer Code (1996) http://www.arcaro.org/tension/

[3] Buchholdt, H.A. (1985) Introduction to Cable Roof Structures. Cambridge University Press, Cambridge.

[4] American Society of Civil Engineers (1996) Structural Applications of Steel Cables for Buildings (ASCE 19-96). American Society of Civil Engineers, Reston.

[5] Nocedal, J. and Wright, S.J. (2006) Numerical Optimization. 2nd Edition, Springer-Verlag, Berlin.

[6] ABNT-NBR 6118 (1993) Design of Concrete Structures-Procedure. Associacao Brasileira de Normas Tecnicas, Rio de Janeiro.

[7] Leonhardt, F. and Mönnig, E. (1986) Vorlesungen über Massivbau: Teil 2 Sonderfälle der Bemessung im Stahlbetonbau (in Portuguese, Rio de Janeiro, Interciencia).

[8] Structurae (2017) https://structurae.net/

[9] Tensinet (2017) http://www.tensinet.com/ 
Submit or recommend next manuscript to SCIRP and we will provide best service for you:

Accepting pre-submission inquiries through Email, Facebook, LinkedIn, Twitter, etc. A wide selection of journals (inclusive of 9 subjects, more than 200 journals)

Providing 24-hour high-quality service

User-friendly online submission system

Fair and swift peer-review system

Efficient typesetting and proofreading procedure

Display of the result of downloads and visits, as well as the number of cited articles Maximum dissemination of your research work

Submit your manuscript at: http://papersubmission.scirp.org/

Or contact ojce@scirp.org 